\title{
PERANAN POESAT EKONOMI RAKYAT MASA PERANG KEMERDEKAAN DI TANAH KARO TAHUN 1943-1945
}

Ika Purnama Sari ${ }^{1}$

Fakultas Ilmu Sosial Universitas Negeri Medan

ikapurnamasari@unimed.ac.id

\begin{abstract}
Abstrak
Penelitian ini bertujuan untuk mengetahui latar belakang dibentuknya POESERA dan peranannya pada perang kemerdekaan di tanah karo pada tahun 1943-1945. Penelitian ini dilakukan di kota Berastagi Kabupaten Karo, karena kantor POESERA pada saat perang kemerdekaan dulu berada di kota tersebut. Untuk memperoleh data-data tersebut, peneliti mengadakan penelitian dengan menggunakan data yang non statistik. Metode yang digunakan adalah penelitian lapangan dengan teknik pengumpulan data berupa wawancara, serta nara sumber yang digunakan adalah orang-orang yang pernah ikut serta dalam perang kemerdekaan di Tanah Karo pada tahun 1943-1945, selain itu penelitian ini juga menggunakan studi kepustakaan dengan menggunakan berbagai buku-buku yang berkaitan dengan perang kemerdekaan. Dari hasil penelitian yang peneliti lakukan menunjukkan bahwa latar belakang berdirinya POESERA (Poesat Ekonomi Rakyat) akibat dari kekejaman Pemerintahan Militer Jepang yang mengakibatkan penderitaan rakyat yang berkepanjangan dan juga tindakan penguasa Jepang yang memonopoli semua kebutuhan dan hasil produksi pertanian rakyat menimbulkan kesulitan-kesulitan bagi kehidupan rakyat. Akhirnya dapat disimpulkan bahwa POESERA dibentuk untuk menyaingi koperasi buatan jepang yang pada saat itu memonopoli hasil-hasil pertanian di tanah karo. POESERA juga menunjukkan bahwa pemuda-pemuda karo saat itu tidak berdiam diri melihat kekejaman yang dilakukan oleh pemerintah militer jepang.
\end{abstract}

Kata kunci : Peranan, POESERA, Karo 


\section{PENDAHULUAN}

Tanah Karo merupakan kata lain dari Kabupaten Karo dalam percakapan sehari-hari, namun sebenarnya anggapan ini sangatlah keliru. Menurut Prinst (2012 :12-13) dalam bukunya Adat Karo maksud dari Tanah Karo adalah daerah-daerah yang di diami oleh suku Karo di Sumatera Utara. Daerah-daerah ini meliputi Sebagian dari Kabupaten Dairi (Kecamatan Taneh Pinem dan Tiga Lingga), Sebagian Kabupaten Deli Serdang (Kecamatan Sibolangit, Pancur Batu, Namo Rambe, Deli Tua, Kutalimbaru, Sibiru-biru, Galang, Bangun Purba dan sebagainya), Sebagian Kabupaten Langkat(Kecamatan Padang Tualang, Bahorok, Kuala, Salapian, Binjai, Stabat dan sebagainya) dan tentunya Kabupaten Karo sendiri. Bahkan "Kampung Medan” juga didirikan oleh Seorang yang bermarga Karo yakni Guru Pa Timpus Sembiring Pelawi.

Tanah Karo tidak luput dari namanya Masa Penjajahan, Belanda memasuki Dataran Tinggi Karo pada tahun 1904 dan memunculkan berbagai macam peperangan yang menelan banyak korban jiwa. Setelah 37 Tahun penjajahan Belanda bercokol di Tanah Karo, Pada tanggal 8 Desember 1941 meletuslah perang Asia Timur Raya dengan Jepang sebagai tokoh utama yang terkenal dengan semboyan 3A nya itu bagi bangsa Asia. Tiga setengah bulan setelah bala tentara Jepang melancarkan serangannya Ke Asia Tenggara, pada tanggal 14 Maret 1942 tentera Jepang berhasil menduduki kota Kabanjahe, serangan Tentera Jepang itu dilakukan melalui Seribu Dolok tanpa mendapat perlawanan yang berarti dari Tentara Belanda.

Pasukan Komando Teritorial Sumatera pimpinan Mayor Jenderal R.T Overakker, yang pada tanggal 9 Maret 1942 telah memindahkan Markasnya ke Kabanjahe, namun ternyata hal itu tidak dapat juga mampu menahan arus serangan tentera Jepang tersebut. Berikutnya pada tanggal 24 Maret 1942 Tiga Binanga dan Kuta Buluh Berteng jatuh dan tentera Belanda melarikan diri ke lembah Alas dan sejak saat itu Tanah Karo Jatuh ke tangan Jepang. Kedatangan tentera Jepang ke daerah ini di bantu oleh anggota Barisan Fuziwara Kikan yang terkenal dengan Barisan tentera " $F$ ", yaitu sejenis pasukan koloni kelimayang bertugas membantu pasukan tempur Jepang. Pada umumnya anggota barisan Tentera "F" ini ialah 
anggota Gerakan Rakyat Indonesia (GERINDO), yang sesungguhnya anti pada kolonialis Belanda, tapu dalam taktik dan politik perjuangannya menggunakan azas koperasi.

Dalam bidang Ekonomi tindakan penguasa Jepang yang memonopoli semua kebutuhan dan hasil produksi pertanian rakyat menimbulkan kesulitan-kesulitan bagi kehidupan rakyat. Kedatangan Saudara Tua (istilah yang dipakai oleh Jepang pada waktu itu) yang semula dianggap akan membawa kebahagiaan dan memerdekakan bangsa Indonesia dari penjajahan, nyatanya melahirkan penderitaan lahir batin yang tiada taranya. Hasil pertanian rakyat dibeli dengan patokan harga yang sangat rendah, barang-barang kebutuhan rakyat hilang dari pasaran dan sebagainya, ini semua mengakibatkan kemelaratan. Karenanya tidaklah heran banyak rakyat petani yang terkena penyakit busung lapar karena padinya telah dirampas, bahkan pakaian sulit untuk ditemukan dan terpaksalah goni dan karet berupa perlak di jadikan pakaian.

Melihat kekejaman-kekejaman yang dibuat oleh pemerintahan militer Jepang, yang berakibat kehidupan rakyat menjadi menderita, hasil-hasil pertaniannya dibeli secara paksa tanpa memikirkan akan kebutuhannya, maka beberapa pemimpin di daerah Karo sangat geram hatinya melihat situasi yang sedang di hadapi oleh rakyatnya. Tokoh-tokoh yang tadinya hanya berpangku tangan, menonton keadaan, kini bersatu padu, bergerak kembali untuk meakukan perlawanan, menggalang kekuatan melalui suatu wadah yang diberi nama Poesat Ekonomi Rakyat, di singkat POESERA.

\section{METODE DAN FOKUS PENELITIAN}

Metode penelitian yang digunakan adalah metode sejarah dengan pendekatan heuristik,kritik sumber, interpretasi, dan historiografi yang berkaitan dengan konsep-konsep sejarah. Penulis menggunakan sumber-sumber tertulis yang terkait dengan peranan POESERA di Tanah Karo. 


\section{HASIL DAN PEMBAHASAN}

\section{Masa Pendudukan Jepang dan Keadaan Ekonomi Tanah Karo}

Sejak balatentera Jepang menguasai seluruh Tanah Karo mereka mengadakan konsolidasi. Pemerintahan pentahbiran Militer Jepang yang di kepalai oleh seorang Gunseibu disusun dan berkedudukan dikota Berastagi. Para pegawai dari zaman Belanda diperintahkan terus bekerja seperti biasa, demikian juga para Raja atau Sibayak tetap memegang pemerintahan di wilayahnya dengan hak dan kedudukan yang diperolehnya dari penjajahan Belanda. Penyerahan kekuasan kepada Raja-raja ini kurang dapat di terima oleh barisan tentera " $F$ " yang pada umumnya terdiri dari pemuda-pemuda GERINDO tapi belum mempermasalahkan ini.

Tidak lama kemudian Barisan Tentera "F" di bubarkan, lalu disusul dengan pembubaran partai-partai politik. Kini tentera Jepang mulai menampakkan belang yang sebenarnya. Kalau pada mulanya partai-partai dibenarkan mengadakan kegiatan, Sang Merah Putih berkibar mendampingi Hinomaru dan Lagu Indonesia Raya bebas berkumandang, maka kini balatentera fascis Jepang memerintahkan untuk membubarkankan partai-partai, melarang dikibarkannya Sang Merah Putih dan dinyanyikann Lagu Indonesia Raya sampai waktu yang tidak ditentukan.

Sejak keluarnya larangan tersebut, kepercayaan rakyat kepada tentara Jepang untuk memperoleh kemerdekaan sebagai bangsa Indonesia menjadi pudar. Memperhatikan perlakuan yang kurang wajar kepada bekas-bekas anggota Barisan tersebut kemudian membentuk wadah-wadah yang baru untuk melanjutkan perjuangan seperti pada saat melawan Belanda dulu. Wadah-wadah tersebut antara lain Sarikat Tani Indonesia dan POESERA (Poesat Ekonomi Rakyat). Sebaliknya para pimpinan Jepang juga tak tinggal diam. Untuk membatasi dan memecahmemecah gerakan-gerakan yang di bentuk secara diam-diam ini mereka membentuk banyak wadah-wadah baru bagi kaum-kaum pribumi. Selain itu mereka juga membutuhkan pasukan yang bisa membantu mereka pada Perang Pasifik yang sedang bergejolak pada saat itu (wawancara dengan bapak M.C Sembiring di LVRI). Mereka membentuk organisasi kemiliteran ala Jepang dan mengorganisirnya dalam susunan kemiliteran juga. Maka berdirilah Barisan 
Mokutai dan Barisan Kyodo Buedan. Barisan-barisan ini pada mulanya di gunakan untuk tujuan Jepang dalam pertahanan dan keamanan mereka, namun pada perkembangannya di dalam banyak para pemimpin gerakan yang mendidik para anggota untuk melawan Jepang. Barisan Mokutai ini di pimpin oleh opsir-opsir lulusan Taman Latihan Pemuda Tani (TALAPETA) di GunungRintis.

Dengan berdirinya Barisan Mokutai disamping Barisan Kyodo Buedan maka dibeberapa desa di Tanah Tinggi Karo hanya terdapat dua Barisan. Kalau Barisan Kyodo Buedan melulu hanya melatih para pemuda untuk pertahanan desa, seperti latihan baris-berbaris, dasar-dasar pertempuran, pengawalan dan pencegahan kebakaran, maka Barisan Mokutai selain memberikan latihan dasar-dasar kemiliteran, juga menanamkan semangat dan rasa cinta terhadap bangsa dan Tanah Air. Barisan Mokutai kepada anggota-anggotanya telah membayangkan akan lahirnya kemerdekaan bagi bangsa Indonesia.

Tindakan penguasa Jepang yang memonopoli semua kebutuhan dan hasil produksi pertanian rakyat menimbulkan kesulitan-kesulitan bagi kehidupan rakyat. Kedatangan Saudara Tua (istilah yang dipakai oleh Jepang pada waktu itu) yang semula dianggap akan membawa kebahagiaan dan memerdekakan bangsa Indonesia dari penjajahan, nyatanya melahirkan penderitaan lahir batin yang tiada taranya. Hasil pertanian rakyat dibeli dengan patokan harga yang sangat rendah, barang-barang kebutuhan rakyat hilang dari pasaran dan sebagainya, ini semua mengakibatkan kemelaratan. Karenanya tidaklah heran banyak rakyat petani yang terkena penyakit busung lapar karena padinya telah dirampas, bahkan pakaian sulit untuk ditemukan dan terpaksalah goni dan karet berupa perlak di jadikan pakaian.

\section{Latar Belakang dibentuknya POESERA dan Pergerakannya}

Melihat kekejaman-kekejaman yang dibuat oleh pemerintahan militer Jepang, yang berakibat kehidupan rakyat menjadi menderita, hasil-hasil pertaniannya dibeli secara paksa tanpa memikirkan akan kebutuhannya, maka beberapa pemimpin di daerah Karo sangat geram hatinya melihat situasi yang sedang di hadapi oleh rakyatnya. Tokoh-tokoh yang tadinya hanya berpangku tangan, menonton keadaan, kini bersatu padu, bergerak kembali untuk meakukan 
perlawanan, menggalang kekuatan melalui suatu wadah yang diberi nama Poesat Ekonomi Rakyat, di singkat POESERA.

Pada rapat pertamanya POESERA langsung membahas bagaimana arah gerakan yang akan di bangun ini. Dalam rapat pertama ini kemudian ditegaskan bahwa POESERA akan mengabdikan dirinya dalam perjuangan dan tindakannya dalam melawan penguasa militer fasis Jepang di Tanah Karo, Bosar Sianipar yang tadinya menjabat Sekretaris Umum merangkap Bendahara POESERA menulis sebagai berikut :

"setelah para pemimpin rakyat melihat dan menilai perilaku Pemerintahan Militer Jepang yang sangat kejam tersebut, maka hal tersebut menimbulkan kegeraman dalam hatinya. Kenyataan pahit inimembikin mereka bangkit bersatu-padu menggerakkan perlawanan. Semua perlawanan, baik dari segi politik, ekonomi dan budaya di konsolider dengan berbagai taktik, strategi dan organisasi. Sebagian tenaga pemuda diarahkan untuk memasuki Heiho (Tentara Sukarela) dan Gyugun (Pembela Tanah Air) untuk mendapatkan pengalaman dan pengetahuan militer."(Surbakti, 1978:16)

Dibidang ekonomi harus segera dibina kesadaran rakyat untuk melemahkan perekonomian militer Jepang. Untuk itu pada awal tahun 1943 didirikanlah Poesat Ekonomi Rakyat, disingkat POESERA. Anggaran dasar Kooperasi POESERA dibentuk secara musyawarah disebuah desa terpencil di Tanah Karo, Kampung Limang. Peneyempurnaan Anggaran dasar kemudian di lakukan di kota Kabanjahe.”(Surbakti,1978:16)

Kedudukan Kantor Pusat POESERA ditetapkan dikota Berastagi sebagai pusat kegiatan, karena di Kota kabanjahe terlebih dahulu telah didirikan satu Badan Koperasi oleh Pemerintah Jepang yang bertujuan untuk menopang ekonomi militer Jepang di Tanah Karo, yang bernaman Sangyo Kumiai. Pengembangan organisasi dan pengumpulan modal POESERA yang di lakukan melaui saluran bekas organisasi Pendidikan Nasional Indonesia ternyata mendapat sambutan yang cukup baik, hal ini di karenakan Tama Ginting juga adalah mantan pengurus Pendidikan Nasional Indonesia (PNI) yang pernah di penjara selama 3 bulan oleh Belanda. Dalam kegiatan pengumpulan modal ini di beritahukan kepada rakyat secara diamdiam, bahwa kegiatan POESERA adalah membela rakyat, memboikot dan menghancurkan ekonomi militer Jepang. 
Pergerakan awal dari POESERA ini telah membuat merekalah yang akan menjadi patron perjuangan dalam melawan kekejaman pemerintahan militer Jepang. Kini POESERA telah lahir di tengah-tengah dentuman meriam fascis Jepang yang berhasrat untuk menguasai manusia dan bangsa-bangsa lainnya di dunia. Di tengan gelap-gulitanya situasi perang Dunia Kedua, POESERA bagaikan Sang Surya Bagi Rakyat Tanah Karo untuk mengatur persiapan dan menyusun perlawanan terhadap kekuasaan militerisme Jepang yang bersemboyankan Asia untuk Asia (hasil wawancara dengan Bapak D. Surbakti di Jaranguda).

Kegiatan POESERA disejajarkan dengan taktik dan strategi yang telah di rencanakan serta disesuaikan dengan situasi yang dihadapi. Setelah POESERA bergerak secara sembunyi-sembunyi selama 8 bulan di mulai dari di bentuknya organisasi pada bulan Januari tahun 1943, maka mulailah organisasi ini menunjukkan giginya dengan mencoba untuk melakukan aksi boikot terhadap kebutuhan ekonomi militer Jepang. Pada bulan Oktober 1943 POESERA melakukan bisikan dan propaganda kepada kepada rakyat agar tidak membawa hasil pertaninan ke pekan Kabanjahe, TigaNderket, Tiga Panah, dan Tiga Binanga yang pada saat itu menjadi pusat hasil-hasil pertanian bagi ekonomi militer Jepang. Bahkan beberapa anggota POESERA melakukan pemblokiran jalan masuk ke pekan dan menyuruh mereka membabat pertanian penduduk yang masih tumbuh. Akibat dari tindakan tersebut dengan serta merta selama seminggu hasil-hasil pertanian rakyat terhenti masuk ke pekan.

Dengan adanya pemboikotan tersebut, Gunseibu sebagai Kepala Pemerintahan Militer Jepang di Tanah Karo menjadi gelisah dan bingung. Pihak penguasa Jepang segera mengadakan penyelidikan, dan akhirnya mengetahui bahwa aksi boikot ini di lakukan atas anjuran dari tokoh-tokoh yang bergabung di dalam POESERA. Seketika itu juga pimpinan dari POESERA di cari oleh Gunseibu yang berkantor di Berastagi, namun mereka tidak ditemukan karena para Pimpinan POESERA tadi telah bersembunyi di berbagai desa di Tanah Karo.

Berdasarkan peristiwa ini selayaknya para pimpinan POESERA ini di jatuhi hukuman mati. Namun satu hal yang menguntungkan pada saat itu adalah, kejadian ini di sampaikan oleh Gunseibu Tanah Karo kepada Raja Mula Manik ( Penghulu 
Kuta Pinang ), seorang tokoh pergerakan yang anti penjajahan Belanda, yang pada saat itu mendapat kepercayaan sebagai pembantu pimpinan Militer Jepang di Medan.

Berkat Lindungan Yang Maha Kuasa, maka atas keluhuran budi dan wibawanya, Penghulu Kuta Pinang membicarakan hal tersebut dengan Gunseikanbu di Medan. Dalam pembicaraannya dengan Gunseikanbu, ia meminta agar pimpinan POESERA tersebut jangan dianiaya atau di bunuh demi ketentraman rakyat Tanah Karo. Permintaan tersebut ternyata mendapat persetujuan dari pihak Gunseikanbu dengan syarat semua tokoh-tokoh yang tergabung dalam POESERA bersedia untuk mengadakan pertemuan dengan Gunseibu di Berastagi.

Dalam pertemuannya dengan Gunseibu di Berastagi, jelas kelihatan sifat jantan serta kebesaran tokoh-tokoh POESERA, yang secara terbuka dan dengan sikap yang pantang mundur tetap membela kebenaran, dengan menjelaskan tindakan-tindakan Pemerintah Jepang yang merugikan rakyat. Memperhatikan sikap terbuka dan kebesaran jiwa pimpinan POESERA dan serta pengaruh Penghulu Kuta Pinang melalui Gunseikanbu di Medan, pihak Gunseibu tidak dapat berbuat apa-apa dan membebaskan mereka dari tuntutan. Setelah berjalan hampir dua tahun POESERA telah mempunyai ribuan anggota di dalamnya yang mayoritas adalah Pemuda.

Sesudah peristiwa tersebut, kegiatan POESERA semakin di tingkatkan. Menjelang Jepang menyerah kepada Sekutu, kantor pusat dipindahkan ke Medan, walau pusat kegiatan masih tetap di Tanah Karo. Dengan kedudukan kantor di Jalan Kapten (sekarang Jalan Pandu No.7) Medan, tokoh-tokoh POESERA mengintegrasikan dirinya dengan tokoh-tokoh pergerakan yang ada di kota Medan. Setelah mengetahui pemerintah Jepang telah bertekuk lutut kepada Balatentara Sekutu, tokoh-tokoh POESERA bertekad bulat untuk meneruskan kegiatan menyusun organisasi guna menghambat masuknya Belanda kembali ke Indonesia. 


\section{PENUTUP}

Keadaan Ekonomi Tanah Karo pada masa pemerintahan militer Jepang sangat memprihatinkan. Penguasa Jepang yang memonopoli semua kebutuhan dan hasil produksi pertanian rakyat menimbulkan kesulitan-kesulitan bagi kehidupan rakyat.. Hasil pertanian rakyat dibeli dengan patokan harga yang sangat rendah, barang-barang kebutuhan rakyat hilang dari pasaran dan sebagainya, ini semua mengakibatkan kemelaratan. Koperasi POESERA (Poesat Ekonomi Rakyat) adalah Organisasi bawah tanah pada zaman Jepang yang pada saat itu inilah Organisasi di Tanah Karo yang tidak memberi keuntungan pada Jepang. Latar Belakang Organisasi tersebut di bentuk akibat dari kekejaman Pemerintahan Militer Jepang yang mengakibatkan penderitaan rakyat yang berkepanjangan dan juga tindakan penguasa Jepang yang memonopoli semua kebutuhan dan hasil produksi pertanian rakyat menimbulkan kesulitan-kesulitan bagi kehidupan rakyat. Untuk itu pada awal tahun 1943 didirikanlah Poesat Ekonomi Rakyat, disingkat POESERA. Pada pergerakannya Koperasi POESERA bertujuan untuk menyaingi Koperasi buatan Jepang yang memonopoli hasil-hasil pertanian rakyat Tanah karo. Selain itu POESERA juga pernah terlibat dalam aksi propaganda kepada kepada rakyat agar tidak membawa hasil pertaninan ke pekan Kabanjahe, TigaNderket, Tiga Panah, dan Tiga Binanga yang pada saat itu menjadi pusat hasil-hasil pertanian bagi ekonomi militer Jepang.

\section{DAFTAR REFERENSI}

Angkasa Edisi Koleksi. 2008. PERANG ASIA TIMUR RAYA Kedigdayaan Dai Nippon. Jakarta. Gramedia.

Bangun, Payung. 1998. Dari Medan Area Ke Sipirok Area. :Yayasan Merga Silima. Gintings, Djamin. 1889. Titi Bambu. Medan. Kalangan Sendiri.

Nakamura, Takasufa. 1985. Perkembangan Ekonomi Jepang Modern. Singapore.Kementrian Luar Negeri Jepang.

Perret, Daniel. 2010. Kolonialisme dan Etnisitas Batak dan Melayu di Sumatra Timur Laut. Jakarta. KPG (Kepustakaan Populer Gramedia).

Singarimbun, Masri. 1992. GARAMATA Perjuangannya Melawan Penjajah Belanda 1901-1905.Jakarta. Balai Pustaka.

Surbakti, A.R. 1979. Perang Kemerdekaan di Karo Area Jilid II. Medan : Yayasan Patria.

Syamsudin, Helius. 2007. Metodologi Sejarah. Yogyakarta : Penerbit Ombak 